\title{
A aplicação da escrita de sinais, Sign Writing, no Brasil
}

\author{
Valdenise Simone Melo Moulin Breda ${ }^{1}$
}

\section{Resumo}

O presente trabalho aborda um tema muito discutido atualmente: a inclusão do ensino adaptado às necessidades da pessoa surda. A pesquisa fundamentou-se na tese de Marianne Stumpf, seguidora do SignWriting, desenvolvido por Sutton, um sistema para representação de gestos, aplicado às línguas de sinais. Além disso, foram analisadas algumas publicações que relataram, aplicaram e desenvolveram esse sistema. Este artigo objetiva divulgar a aplicação da escrita de sinais no Brasil, para que esta possa ser adaptada e utilizada pelas instituições educacionais. O sistema SignWriting pode se tornar uma ferramenta de tradução dos conteúdos necessários ao ensino-aprendizagem, porque funciona como um canal de comunicação entre educadores e alunos surdos e vice-versa. Um exemplo dessa funcionalidade é a produção de apostilas e apresentações digitais com textos e legendas nessa escrita, agilizando e facilitando a comunicação de conteúdos curriculares.

Palavras-chave: surdez, escrita de sinais, SignWriting, LIBRAS.

${ }^{1}$ Servidora Pública - Instituto Federal do Espírito Santo - Campus de Alegre. Pósgraduada Lato Sensu em LIBRAS - Faculdade Educacional da Lapa. E-mail: vsimone@, ifes.edu.br 


\section{Abstract}

The present paper addresses a very discussed topic: the inclusion of education adapted to the needs of deaf people. The research was based on the thesis of Marianne Stumpf, follower of the SignWriting system developed by Sutton, a system for gesture representation, applied to sign languages. In addition, some publications have analyzed that they reported, applied and developed this system. The purpose of this article was to promote the application of SignWriting in Brazil, so that this system can be adapted and used by educational institutions. The SignWriting system can become a tool for translating the necessary contents for teachinglearning because it functions as a communication channel between teacher and deaf students and vice versa. And an example of this functionality is the production of handouts and digital presentations with texts and subtitles in this writing, streamlining and facilitating the communication of curricular contents.

Keywords: deaf, SignWriting, LIBRAS.

Atualmente, um dos temas que faz parte do cotidiano da sociedade é a inclusão. Ela está representada nos locais públicos através de marcadores nas calçadas, semáforos sonoros, rampas etc. Estamos saindo da cultura do exclusivo para a cultura do inclusivo. Esta é uma experiência de alteridade. Neste artigo, a inclusão abordada foi a necessidade específica das pessoas surdas. Stumpf (2005, p. 38) comenta que o governo brasileiro, através do MEC, "está patrocinando uma grande mudança na educação dos surdos no Brasil, cujo [...] objetivo primeiro é a inclusão da população surda nas escolas de ouvintes". Para alavancar esse empreendimento, há um sistema de escrita de sinais que pode auxiliar a comunidade surda por meio da educação. O educador, nas salas inclusivas ou nas turmas de licenciatura, poderá utilizá-lo em suas aulas. 
$\mathrm{E}$ por que escrever um artigo sobre esse tema? Baseado na Lei 10.436 de 24 de abril de 2002, "é reconhecida como meio legal de comunicação e expressão a Língua Brasileira de Sinais (Libras) e outros recursos de expressão a ela associados”, e Albres (2013, p. 100) afirma que "a LIBRAS é uma língua oficial no Brasil”. E o sistema SignWriting, que é a língua escrita de sinais, pode auxiliar na divulgação da LIBRAS e ser uma ponte entre esta e a língua portuguesa escrita.

Também, hipoteticamente falando, se houvesse uma pesquisa estatística para saber quantas pessoas conhecem a escrita de sinais, o resultado seria quase nulo. São raras as pessoas que conhecem o SignWriting, a escrita de sinais, em consonância com o que Wanderley (2012, p. 38) declara: "no Brasil, há pouquíssimas pesquisas sobre o ensino da escrita de sinais". Por isso, é relevante a publicação dessa ferramenta comunicativa tanto para surdos, que terão acesso mais ágil a qualquer forma de conhecimento, como para ouvintes que necessitam se comunicar com os surdos. A semelhança existente entre o SignW riting e a LIBRAS permite ao surdo apreender um conhecimento novo de forma menos impactante do que se tivesse que aprender na Língua Portuguesa, visto que, para o surdo, ela é considerada segunda língua.

Conforme explicam Formagio e Lacerda (2016, p. 181), o ensino da comunicação escrita é diferente do aprendizado da comunicação verbal (para os ouvintes) e da comunicação gestual (para os surdos), que ocorre de forma natural. Esse ensino necessita de uma ação planejada e adequada, processada em uma experimentação de condicionamento intelectual. "A escrita é um sofisticado sistema de representação simbólica da realidade que, como todo signo, media a relação dos homens com o mundo”.

O sistema que se pretende abordar é o da escrita de sinais, chamado SignWriting. O objetivo da presente pesquisa foi estudar a aplicação dessa escrita no Brasil, analisando o seu desenvolvimento, focando na problemática da inclusão por meio da escrita, e abrindo um espaço de discussão teórica sobre a importância de conhecê-lo. "Infelizmente, a 
escrita de sinais é um acontecimento recente em nosso meio, considerando que o planejamento linguístico na consolidação da escrita de sinais é aceito a inclusão e como tal precisa acontecer na Educação Básica" (WANDERLEY, 2012, p. 50-51).

Segundo Formagio e Lacerda (2016, p. 190-191), há “discussões políticas" na atualidade sobre "um modelo bilíngue [...] para o ensino de surdos". E o que se observa é que há uma necessidade de pesquisas aplicadas sobre o assunto para auxiliar nas metodologias e práticas diárias de salas de aula inclusivas, necessitando de professores bilíngues que atendam ao mesmo tempo alunos ouvintes e surdos. O quadro profissional das escolas é formado por técnico-administrativos e docentes sem preparação para recepcionar os alunos surdos ou trabalhar com os alunos ouvintes e surdos ao mesmo tempo. Para solucionar esse problema de imediato, necessita-se hoje de intérpretes de LIBRAS em salas de aula inclusivas. Porém, na contratação de novos profissionais, é necessário que estes ou sejam professores/intérpretes ou saibam utilizar a língua escrita de sinais como forma de comunicação, por exemplo, em apresentações de textos e imagens e apostilas escritas em SignWriting.

Nas referências deste artigo encontram-se obras e sítios eletrônicos que pretendem servir de uma introdução ao estudo da língua escrita de sinais. As páginas eletrônicas levarão a publicações que utilizam o sistema e a outros endereços eletrônicos que também fazem uso ou divulgam a língua escrita de sinais. São ambientes educacionais propícios ao saber e ao desenvolvimento desse sistema, funcionando também como recursos didáticos que podem ser utilizados com alunos surdos e ouvintes.

A história do sistema SignWriting se iniciou com a sua desenvolvedora, Valerie Sutton, uma especialista em movimentos do Centro para a Escrita do Movimento, que leva o seu nome. No caso da escrita de sinais, os movimentos observados são da língua de sinais que a autora descreveu, representando-os no papel ou no computador. A obra de Sutton, Lições sobre o SignWriting: um sistema de escrita para lingua de sinais, 
foi traduzida e adaptada por Marianne Rossi Stumpf. A justificativa para a adaptação é que, segundo a tradutora, "alguns símbolos do manual original foram excluídos, uma vez que não eram produtivos na língua de sinais brasileira". A obra é constituída de lições sobre o SignWriting, explicações e atividades que funcionam como um manual e o leitor interessado consegue entrar no rico sistema de comunicação da escrita de sinais.

A fundamentação teórica do estudo apresentado é a tese de Stumpf, ela que é surda e desenvolveu pesquisa sobre a escrita de sinais para "servir de suporte a uma nova proposta pedagógica ao ensino da escrita de sinais e letramento para crianças surdas usuárias da Língua Brasileira de sinais - LIBRAS" (STUMPF, 2005, p. 14). Apesar da tese de Stumpf falar sobre o estudo de crianças surdas, ela é aplicável a qualquer faixa etária, pois, ao iniciarmos o aprendizado num sistema de línguas novo, pode-se observar o comportamento de aprendizagem infantil e adaptá-lo às idades posteriores, como se pode depreender da obra de Vygotsky, A construção do pensamento e da linguagem, que demonstra justamente isso: como ocorre o processo de construção do pensamento e da linguagem. Vygotsky (2001, p. 430), baseado no estudo de Piaget, analisa a evolução do pensamento e da linguagem. À medida que a criança vai interagindo socialmente, seu pensamento e sua linguagem evoluem, partindo da linguagem egocêntrica, passando pela linguagem interior, até chegar na linguagem social. A sociedade necessita de se comunicar e utiliza a linguagem. Esta, para os ouvintes, é desenvolvida através da audição e da fala. Os surdos desenvolvem a comunicação gestual e expressiva; para eles, é natural gesticular e expressar-se fisionomicamente, e o sistema SignWriting pode ser o canal entre a LIBRAS e a Língua Portuguesa.

Outro estudo desse sistema, que pesquisou estudantes de diferentes faixas etárias, é a dissertação de Débora Campos Wanderley, Aspectos da leitura e escrita de sinais: estudos de caso com alunos surdos da educação 
básica e de universitários surdos e ouvintes, que consiste em estudos de caso de aplicação da língua escrita de sinais com alunos surdos e ouvintes dos níveis educacionais citados no título, que revelaram uma metodologia comparativa adaptável para ser aplicada com faixas etárias diferenciadas. Wanderley (2012, p. 25), "praticamente surda desde o nascimento", compartilha sua experiência como aluna e procura uma forma de auxiliar no processo de ensino-aprendizagem de outros alunos surdos e ouvintes, para obterem êxito na aprendizagem de línguas.

Ainda sobre a história da língua escrita de sinais, é interessante relatar a obra Um capitulo da bistória do SignWriting, de Quadros (1999). Essa obra se encontra num endereço eletrônico que contém, dispostos ao redor da narrativa, sinais escritos que levam a outras janelas, como hiperlinks, onde é possível acessar vendas de livros e bibliotecas com livros e vídeos, entre outras informações.

Já o trabalho de TCC da autora Campos, intitulado $A$ escrita de sinais no Brasil sob olhar da comunidade acadêmica, reflete sobre a importância da divulgação da escrita de sinais, tal como ela afirma: "apesar de o sistema SignWriting significar a conquista de uma forma própria de registro para a Língua Brasileira de Sinais, ainda há poucos conhecedores e usuários dessa ferramenta" (CAMPOS, 2012, p. 24).

A metodologia utilizada compreendeu uma revisão literária do assunto, utilizando referências impressas e digitais como dissertações, teses, livros e artigos.

Para continuar falando sobre SignWriting é necessário saber o que são gestos e signos visuais. Saussure (1915 [2006], p. 79-80) alerta que o signo linguístico possui natureza psíquica, porque em nosso cérebro são registradas associações do significante (imagem acústica para os ouvintes, ou imagem gestual e expressão fisionômica, para os surdos) e do significado. Vygotsky (2007, p. 128) declara que "o gesto é o signo visual inicial que contém a futura escrita da criança, assim como uma semente contém um futuro carvalho. [...] Os gestos são a escrita no 
ar, e os signos escritos são, frequentemente, simples gestos que foram fixados". E fixaram-se num sistema de escrita de sinais.

Stumpf (2005, p. 57; 61-62; 227) certifica que "o SignWriting é dividido em dez categorias: mãos, contato das mãos, faces, movimentos do corpo e da cabeça, ombros, membros, inclinação da cabeça, localização, movimento de dinâmicas e pontuação", como se pode observar nas quatro figuras seguintes:

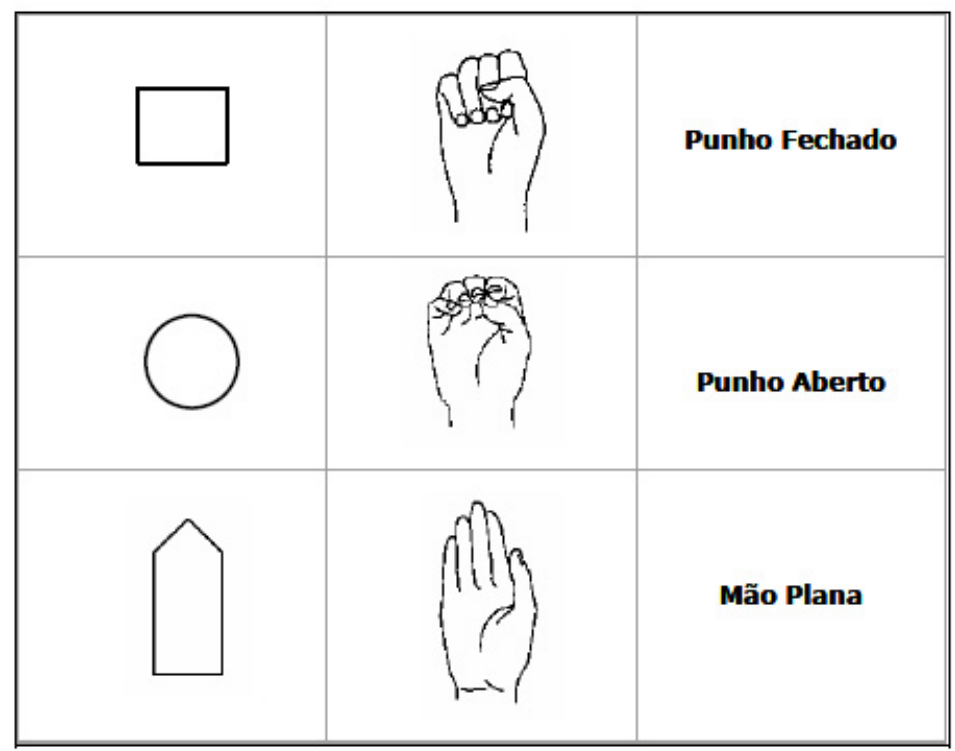

Figura 1 - configurações das mãos - escrita de sinais encontra-se na $1^{a}$ coluna 
Adicionar linhas para os dedos

\begin{tabular}{|l|l|l|}
\hline \hline & Mão Indicadora \\
\hline & Mão - D \\
\hline
\end{tabular}

Figura 2 - configurações das mãos - escrita de sinais se encontra na $1^{\mathrm{a}}$ coluna

\section{Ponto de Vista Expressivo}

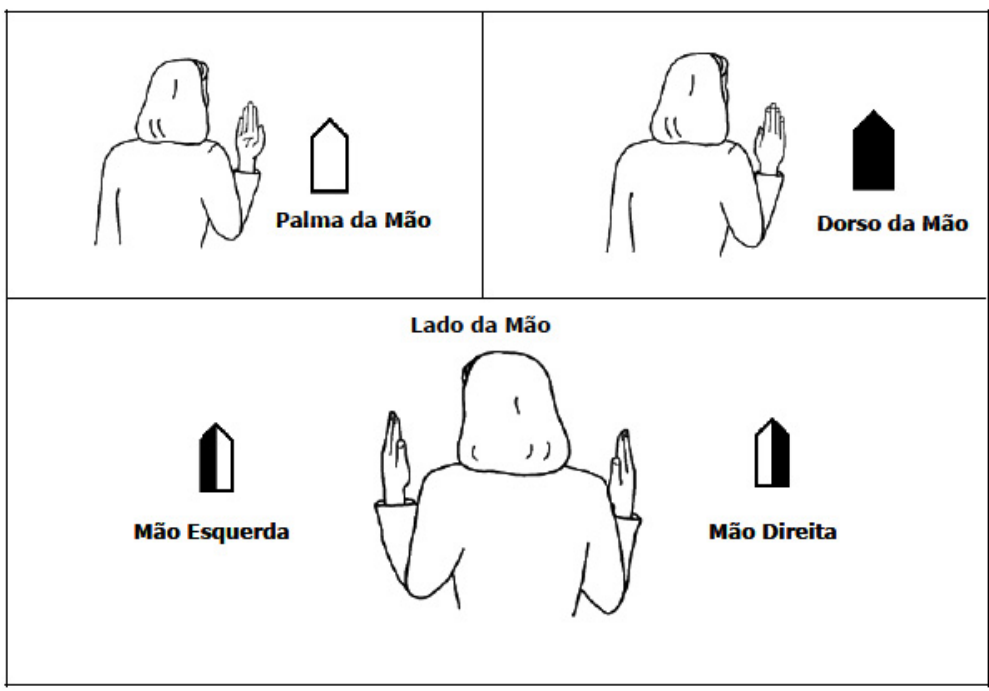

Figura 3 - Configurações das mãos 


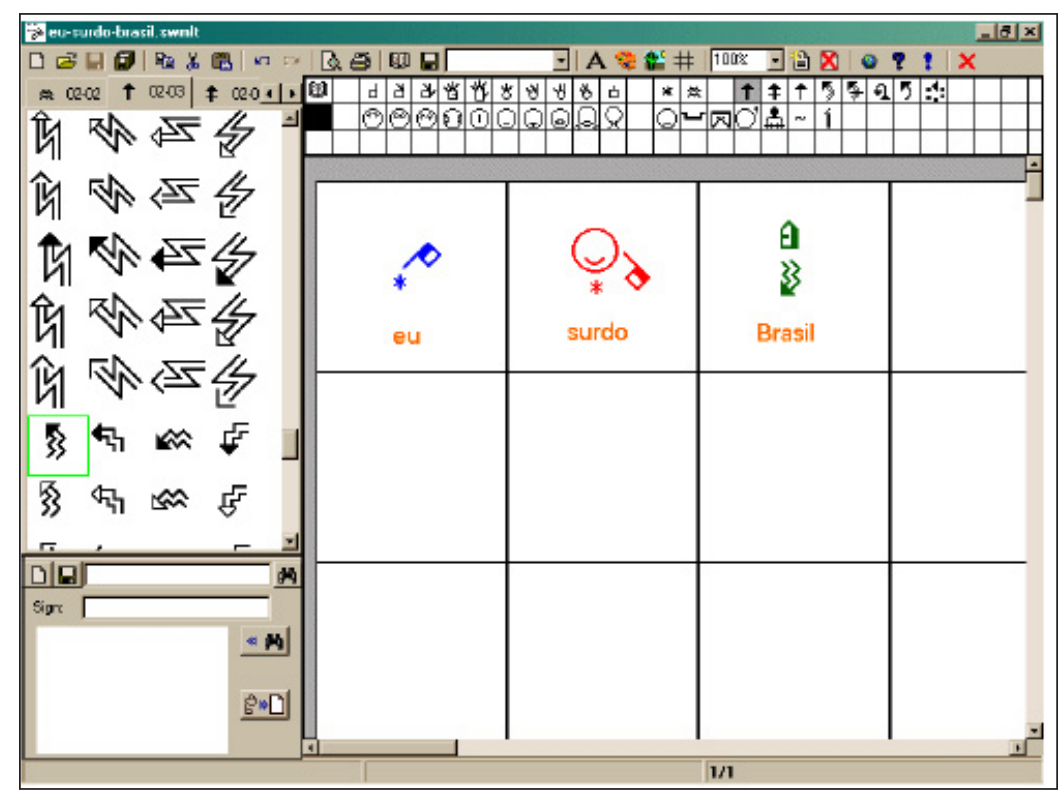

Figura 4 - exemplo de software SignWriting edit - aplicativo para usar a escrita de sinais no computador

Segundo Stumpf (2005, p. 226), o aplicativo SW-Edit "pode ser descrito como uma interface projetada para pessoas surdas, visando a edição de textos por meio do sistema de ELS denominado SignWriting". É uma ferramenta que permite "inclusão de textos em português; inserção de figuras e imagens; base de dados expansível; possibilidade de fazer traduções; dicionário de sinais".

Segue a figura 5 com um teclado de teclas especiais para escrita de sinais (STUMPF, 2005, p. 229): 
Manual do Sign Writer - teclado do Sign Writer

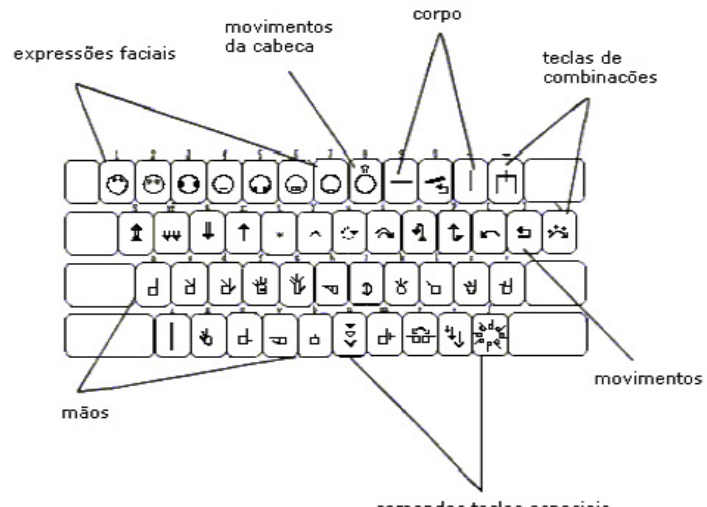

comandos teclas especiais

Figura 5 - teclado do Sign Writer

TeClas especiais

Há também um teclado do SignWriting que não está aqui ilustrado, mas que pode ser visto na tese de Stumpf.

Abaixo, um exemplo de escrita de sinais de Sutton (1999):

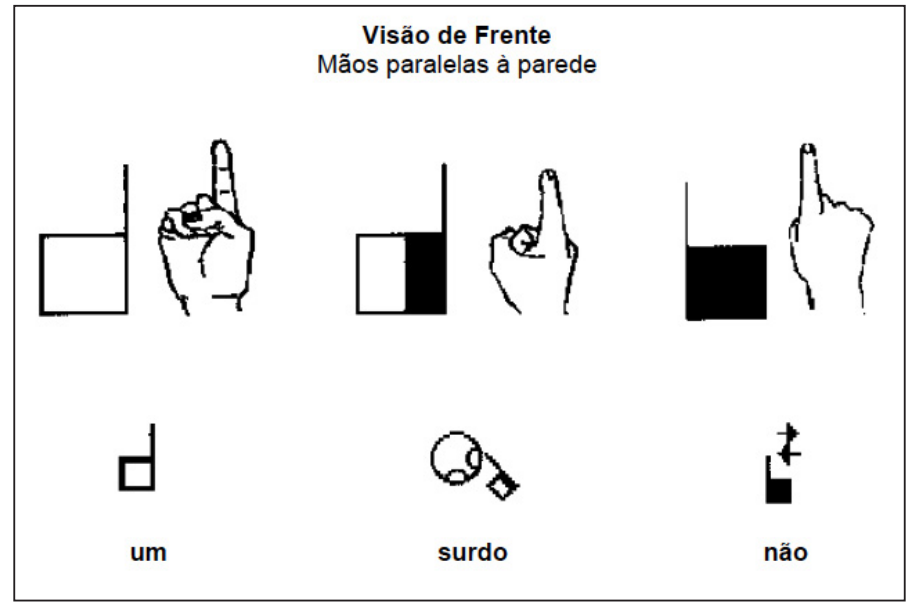

Figura 6 - exemplo de escrita de sinais segundo Sutton 
A escrita é um produto cultural, segundo Formagio e Lacerda (2016, p. 181), e "apropriar-se" dela "é construir uma nova inserção social, interagir com os conhecimentos produzidos e acumulados historicamente. Ler e escrever são condições básicas para acesso à informação e produção de novos conhecimentos"; estendem os relacionamentos sociais através dos tipos de discurso e durante o processo de montagem dele. O discurso sofre "interferência das sociedades 'tecnologizadas', que exigem diferentes usos e funções da escrita, e é conceituada pela terminologia letramento" (FORMAGIO; LACERDA, 2016, p. 183).

A aplicação da língua escrita de sinais em sala de aula, conforme Stumpf (2005, p. 44) comenta, auxilia os alunos surdos, porque "quando as crianças conseguem aprender uma escrita que é representação de sua língua natural têm oportunidade de melhorar todo seu conhecimento cognitivo". No relato das primeiras aulas, Stumpf (2005, p. 106) conta e apresenta ilustrações de como seus alunos iniciam a aprendizagem do SignWriting:

Desenham os objetos, desenham mãos sinalizando, começam a observar os símbolos apresentados pela apresentadora e vão conseguindo diferenciá-los qualitativa e quantitativamente, compreendem que eles correspondem aos sinais das Libras e aprendem a estabelecer correspondência entre os sinais e os símbolos do SignWriting.

Outra parte da tese de Stumpf (2005, p. 119-244) muito interessante são os relatos diários das aulas que ela lecionou em uma escola para surdos. Através deles, podem se adaptar métodos e atividades, além de análises das reações dos alunos a cada procedimento didático. No primeiro relato, Stumpf (2005, p. 119-120) fala que contou uma história em LIBRAS e depois solicitou aos alunos para que desenhassem sobre a história. Os desenhos apresentaram uma combinação de "mãos sinalizando e personagens" conforme exemplo abaixo: 


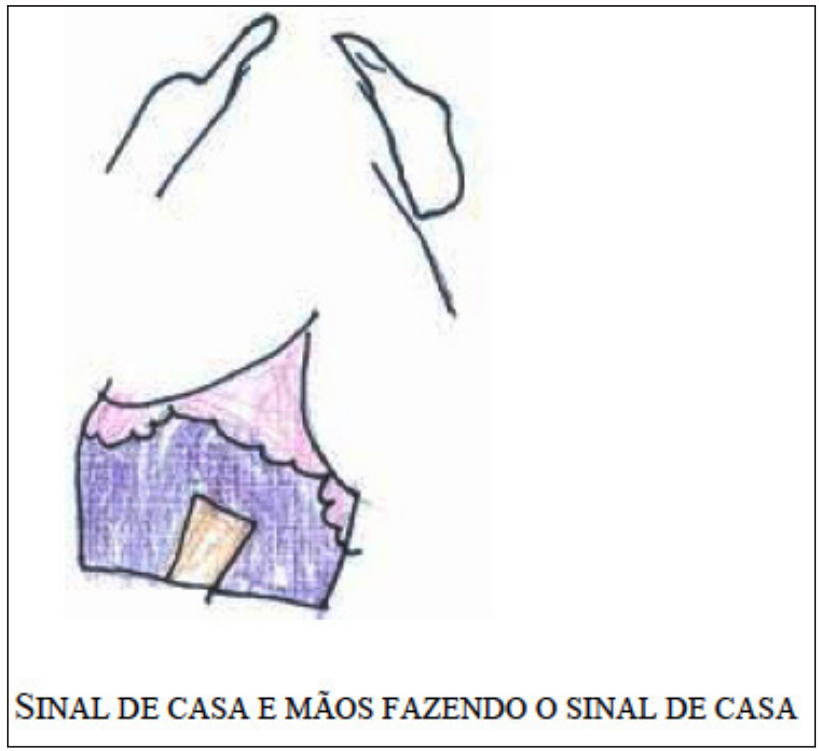

Figura 7 - desenho de aluno de uma escola para surdos sobre sua história

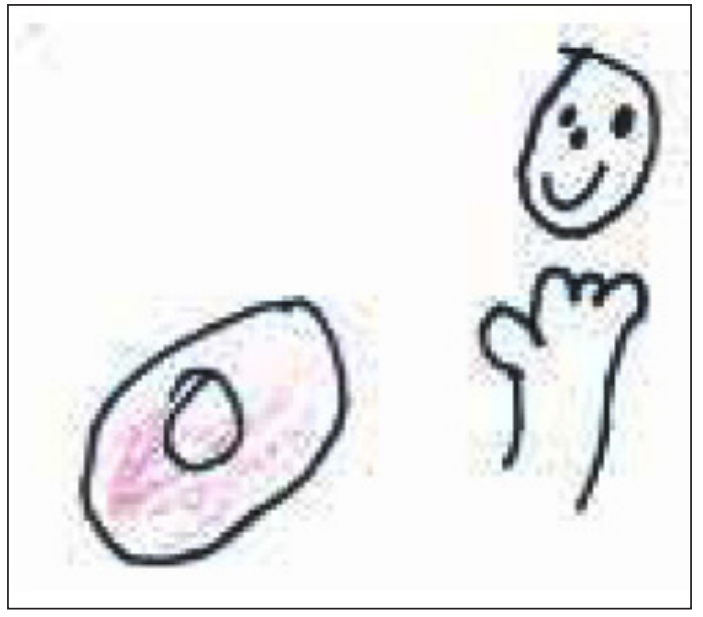

\section{SINAL DE COMER E DESENHO DE PRATO}

Figura 8 - desenho de aluno de uma escola para surdos sobre sua história 
As figuras 7 e 8 representam duas abordagens, duas visões: a imagem do que se quis representar - nos casos, uma casa e um prato, respectivamente - , e, ao lado, uma tentativa de desenhar a imagem da língua de sinais representando a casa e o prato, demonstrando uma compreensão das crianças sobre a possibilidade de uma língua de sinais escrita (STUMPF, 2005, p. 216).

No segundo encontro, Stumpf (2005, p. 119-121) relata que levou vários cartazes com meses, dias da semana e outros com escritas de sinais e palavras correspondentes escritas em língua portuguesa etc. Essa atividade teria um efeito melhor se houvesse três colunas contendo cada um dos seguintes fatores, nesta ordem: escritas de sinais, palavras correspondentes escritas em língua portuguesa e a imagem relacionada.

No terceiro encontro, Stumpf (2005, p. 123) recebeu de seus alunos a notícia de que seus pais haviam se interessado pela escrita de sinais. Isso significou que os alunos estavam gostando das aulas e compartilhando o conhecimento com os pais, e que estes reconheceram a utilidade da língua escrita de sinais.

Em outro encontro, depois de muitos treinos e explicações, foi proposto um jogo de mímica muito interessante que apresentava "os quatro tipos de grafia: o sinal completo (pilha) em SignWriting, desenho do animal, dactilologia escrita em SignWriting e português" (STUMPF, 2005, p. 141), conforme figura abaixo: 


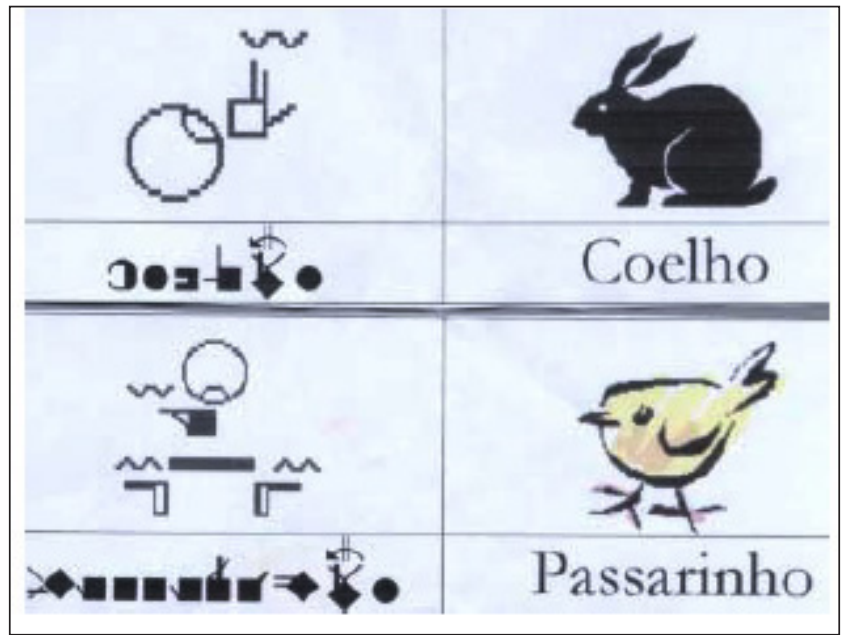

JOGO DA MÍMICA

Figura 9 - jogo de mímica

Sobre os jogos didáticos, Stumpf (2005, p. 223) afirmou que "são recursos importantes para aprendizagem da leitura e da escrita, desenvolvem também as atitudes de comportamento, convivência, organização e participação. As crianças gostam muito de jogar".

O objetivo da pesquisa de Stumpf foi:

Compreender como as crianças e jovens surdos se apropriam da língua escrita de sinais e de que forma o acesso ao computador por meio de softwares com ELS, pelo sistema SignWriting, pode dar suporte a essa aquisição (STUMPF, 2005, p. 213)

Segundo Stumpf (2005, p. 214), fundamentada na teoria de Piaget, a representação de objetos ou de situações que estejam ausentes por meio de imagens mentais "é a condição básica para o pensamento existir". E nesta linha de raciocínio é possível "recordar e planejar. Associar suas ações no espaço e no tempo. Reconhecer-se como diferente dos outros indivíduos". 
A metodologia utilizada por Stumpf (2005, p. 215) foi trabalhar com os alunos surdos a partir de seus interesses despertados "pelo próprio objeto de conhecimento proposto e em conversas em sinais, para, com a utilização dos recursos didáticos disponíveis, iniciarmos a apropriação do sistema SignWriting de escrita de língua de sinais". A adaptação pela qual os alunos surdos passam do aprendizado da utilização da LIBRAS para a escrita de sinais, SignWriting, é a mesma que ocorre com os alunos ouvintes ao passarem do uso da língua oral para a língua escrita, conforme Stumpf (2005, p. 218).

No processo de aprendizagem, ou de passagem da LIBRAS para a língua escrita de sinais, Stumpf (2005, p. 220-221) observa dois aspectos: um afetivo e um de evolução na aprendizagem. No primeiro, o aluno surdo consegue estabelecer semelhanças entre a LIBRAS e a escrita de sinais, é

O reconhecimento de que sua língua de sinais também é importante, também pode ser escrita, a relação que se estabelece entre os colegas para cooperar e trocar conhecimentos, as produções animadas, o poder contar em casa que são possuidores de um $\mathrm{c} \mathrm{o} \mathrm{n} \mathrm{h} \mathrm{e} \mathrm{c} \mathrm{i} \mathrm{m} \mathrm{e} \mathrm{n} \mathrm{t} \mathrm{o}$ reconhecido pela escola, são fatores entre outros, de apropriação de um sentimento de auto-estima, do qual elas muitas vezes carecem e de empenho em aprender (STUMPF, 2005, p. 220-221).

No segundo aspecto, a evolução na aprendizagem pode ser apreciada no dinamismo demonstrado no desempenho que os alunos surdos têm com o sistema SignWriting, além de aumentar o conhecimento de sinais e desenvolver a comunicação, tornando-os mais receptivos ao aprendizado. O que não ocorria quando se ensinava a língua portuguesa escrita sem fazer esse vínculo com a língua de sinais escrita, porque se a linguagem do surdo possui uma constituição diferente, seu raciocínio e sua lógica serão diferentes, dificultando o aprendizado imediato, necessitando de uma ponte, de um tempo de adaptação diferente. 
Stumpf (2005, p. 221) afirma que quando os pais dos alunos surdos se interessam em aprender a LIBRAS e a língua escrita de sinais, esta ação auxilia no interesse dos alunos por ficarem motivados a se comunicarem em casa.

Em um dos relatórios de Stumpf (2005, p. 236), ela relata que os alunos estavam ansiosos para utilizar o programa do SignWriting e que, apesar de ter explicado a eles que a atividade fluiria melhor se fossem três por computador - para haver interação e evolução do trabalho com desenvolvimento da aprendizagem -, os alunos começaram a discutir e ficaram agitados para ver quem sentava diante do computador. Isso fez com que ela trocasse de atividade para desenho de escrita de sinais no Paint, a fim de deixar o plano inicial de trabalho para outra ocasião. Essa foi uma tática interessante, que pode ser utilizada em momentos de conflito ou de impasse. Em outros encontros, Stumpf fez algumas tentativas, até ter a ideia de distribuir um manual de como utilizar o programa. Dessa forma, os alunos iniciaram o aprendizado através de tentativas no programa.

Considerando tudo o que foi apresentado neste estudo e observando as figuras acima expostas, a escrita de sinais é a representação gráfica da língua de sinais, sendo facilitadora no ensino-aprendizagem e na comunicação de quaisquer informações aos surdos. Os estudos fundamentados na aplicação do sistema da escrita de sinais no Brasil demonstraram que houve uma inclinação para agilizar e facilitar o ensinoaprendizagem dos surdos, e que continua havendo um desconhecimento da escrita de sinais por uma parcela considerável da população brasileira, mas a tendência é, aos poucos, que os professores que trabalham com LIBRAS acabem conhecendo a escrita de sinais através de estudos e pesquisas em sítios eletrônicos e em outras publicações e comecem a trabalhar com seus alunos surdos, proporcionando um desenvolvimento intelectual maior. Assim, também os alunos ouvintes presentes em salas inclusivas poderão se familiarizar com a língua de sinais.

Segundo Stumpf (2005, p. 266), 
O sistema SignWriting apenas começa a ser usado pela população surda e seu uso precisa ser acompanhado por pesquisas linguistas que possam observar e procurar soluções cada vez mais econômicas para sua utilização (STUMPF, 2005, p. 266).

Tratando-se de línguas, observou-se a afinidade dos cursos de Letras e LIBRAS, com destaque aos professores de língua portuguesa, pois eles teriam um conhecimento linguístico já adquirido que facilitaria a nova aprendizagem e, ao mesmo tempo, estariam ensinando a língua portuguesa.

$\mathrm{Na}$ era tecnológica em que se vive, o aplicativo SignWriting Edit permite que o surdo se comunique através da rede, estando incluído no espaço digital.

Observou-se também que a Universidade Federal de Santa Catarina (UFSC) se destaca no desenvolvimento de estudos sobre o sistema SignWriting, através das pesquisas realizadas nos cursos de pósgraduação com as comunidades universitária, de ensino básico e surda.

Analisando os relatos de Stumpf, observou-se que, para ensinar a escrita de sinais, ela utilizou muitos jogos como dominó, cartas, memória etc., trabalhando o lúdico no ensino-aprendizagem.

Stumpf (2005, p. 269-270), dentre várias considerações, em uma delas afirmou: "quanto às relações entre o português escrito e o SignWriting, uma abordagem científica implicaria a comparação de dois grupos: um adquirindo só o português escrito, outro, os dois sistemas”. A autora justifica deixar em aberto a questão, porque em se tratando de

Uma pesquisa exploratória, ela não traz respostas conclusivas, mas sugere novas pesquisas que aperfeiçoem as condições dessa apropriação, e ainda interroga a comunidade de pesquisadores preocupados com a educação dos surdos, da informática e da linguística a responder a questão de se a compreensão do processo de aquisição da ELS poderá ajudar a construir metodologias mais naturais para o surdo aprender a língua portuguesa escrita (STUMPF, 2005, p. 271). 
O sistema SignWriting pode se tornar uma ferramenta de tradução dos conteúdos necessários ao ensino-aprendizagem, devido ao fato de poder funcionar como um canal de comunicação entre educadores e alunos surdos e vice-versa. Um exemplo do uso do sistema SignWriting é a possibilidade de o educador produzir apostilas e apresentações digitais com os textos e as legendas nesta escrita para atender aos alunos surdos, agilizando e facilitando a transmissão de informações e conteúdos curriculares. Esse sistema é muito próximo da LIBRAS, e isso estimula o aluno surdo a ultrapassar o primeiro impacto da organização escolar, como as disciplinas, os materiais escolares, as atividades, as avaliações, o ambiente de sala de aula e a convivência social, e depois o leva a se interessar pelo aprendizado da língua portuguesa e de outras línguas.

\section{Referências}

ALBRES, N. de A. Comunicação em LIBRAS: para além dos sinais, o que é importante conhecer? In: LACERDA, C. B. F. de; SANTOS, L. F. dos (Orgs). Tenho um aluno surdo, e agora? Introdução à LIBRAS e educação de surdos. São Carlos: EdUFSCar, 2013.

CAMPOS, S. A. U. de S. A escrita de sinais no Brasil sob olhar da comunidade acadêmica. Maringá: UEM, 2012. Disponível em: $<$ http://webcache.googleusercontent.com/search?q=cache:SpXUMIN_ pAcj:www.dfe.uem.br/TCC/Trabalhos_2012/SIMONE_AYUMI_UETA. $\mathrm{pdf}+\& \mathrm{~cd}=7 \& \mathrm{hl}=\mathrm{pt}-\mathrm{BR} \& \mathrm{ct}=\mathrm{clnk} \& \mathrm{gl}=\mathrm{br}>$. Acesso em 13 ago. 2016.

FORMAGIO, C. L. S.; LACERDA, C. B. F. de. Práticas pedagógicas do ensino de português como segunda língua para alunos surdos no ensino fundamental. In: LACERDA, C. B. F. de; SANTOS, L. F. dos. MARTINS, V. R. de O. (Orgs). São Carlos: EdUFSCar, 2016. 
BRASIL. Lei $\mathrm{N}^{\circ} \mathbf{1 0 . 4 3 6}$ de $\mathbf{2 4}$ de abril de 2002. Dispõe sobre a Língua Brasileira de Sinais - Libras e dá outras providências. Disponível em: $<$ http://www.planalto.gov.br/ccivil_03/leis/2002/L10436.htm> Acesso em 13 ago. 2016.

QUADROS, R. M. de. Um capítulo da história do Signwriting. Disponível em: <http://www.signwriting.org/library/history/hist010. html>. Acesso em 31 jul. 2016.

SAUSSURE, F. Curso de Linguística geral. São Paulo: Cultrix, 1915 [2006]. Disponível em: < https://monoskop.org/images/1/1f/Saussure_ Ferdinand_de_Curso_de_linguistica_geral_27_ed.pdf > Acesso em 31 jul. 2016.

STUMPF, M. R. Aprendizagem da escrita de língua de sinais pelo sistema de SignWriting: língua de sinais no papel e no computador. Tese de Doutorado. Porto Alegre, UFRGS, 2005. Disponível em: <www.lume. ufrgs.br/bitstream/handle/10183/5429/000515254.pdf?...1> Acesso em 13 ago. 2016.

SUTTON, V. Lições sobre o SignWriting: um sistema de escrita para língua de sinais. Tradução: Marianne Rossi Stumpf - Tradução Parcial e Adaptação do Inglês/ASL para Português LIBRAS do livro "Lessons in SignWriting", de Valerie Sutton, publicado originalmente pelo DAC Deaf Action Committe for SignWriting. Disponível em: <http://www. signwriting.org/archive/docs5/sw0472-BR-Licoes-SignWriting.pdf> Acesso em 29 jul. 2016.

VYGOTSKY, L. S. A construção do pensamento e da linguagem. São Paulo: Martins Fontes, 2001. 
A formação social da mente: o desenvolvimento dos processos psicológicos superiores. 7. ed. São Paulo: Martins Fontes, 2007.

WANDERLEY, D. C. Aspectos da leitura e escrita de sinais: estudos de caso com alunos surdos da educação básica e de universitários surdos e ouvintes. Florianópolis: UFSC, 2009. Disponível em: < https:// repositorio. ufsc.br/bitstream/handle/123456789/100775/308896.pdf?...1> Acesso em 29 jul. 2016. 